\title{
PENTINGNYA MANFAAT PIJAT BAYI PADA BAYI USIA 0-12 BULAN
}

\author{
Nurwinda Saputri \\ Prodi DIII Kebidanan \\ STIKes Muhammadiyah Pringsewu, Jln. Makam KH Ghalib No 112 Pringsewu \\ Lampung/072922537 \\ E-mail: nurwindasaputri17@gmail.com
}

\begin{abstract}
The Tri Dharma College's Activity on Community Service is to help knowledge and how to do baby work, because this is very important for optimally developing babies. This service provides provisions on how to massage the right baby. The target of this service is approved by mothers who have babies aged 0-12 months. The settlement was completed with 3 solutions, namely Planning, Implementation and Evaluation, in planning activities carried out by means of a preliminary survey, this activity was carried out to see conditions in the field regarding infant massage. The training was conducted by conducting lectures by lecturing the presentation technique and then continued with demonstration of the practice of baby massage. Evaluation of this activity is carried out at each stage of massage. The results in this baby massage training activity are in accordance with the needs of the mothers in assisting infant development. This baby massage can make the baby feel comfortable, and relax, massage makes the baby's muscles tenuous, baby massage can help improve, train brain development, relieve digestion, and help oxygen to the brain. A good response (80\%) can overcome the baby's massage. However, some of them who have never done a massage to their baby, become fearful mothers, but there is no need to worry because this activity can be done casually at home by reading the Booklet carefully. The results of community service are expected to motivate and increase the skills of mothers in infant massage.
\end{abstract}

Keywords: Benefits of Massage, in Infants, Development of Infants

\begin{abstract}
Abstrak
Kegiatan Tri Dharma Perguruan Tinggi tentang Pengabdian kepada Masyarkat ini adalah bertujuan untuk memberikan ilmu pengetahuan dan cara bagaimana melakukan pija bayi, karna hal ini sangat penting untuk membantu perkembangan bayi secara optimal. Pengabdian ini memberikan bekal bagaimana cara memijat bayi yang benar. Sasaran pengabdian ini berfokus pada ibu-ibu yang memiliki bayi usia 0-12 bulan. Penyelesaian ini diselesaikan dengan 3 tahapan penyelesaian, yaitu Perencanaan, Pelaksanaan dan Evaluasi, dalam kegiatan perencanaan ini dilakukan dengan cara survey pendahuluan, kegiatan ini dilakukan untuk melihat kondisi di lapangan mengenai pijat bayi. Pelaksanaan dilakukan dengan melakukan training dengan cara ceramah yaitu degan teknik presentasi kemudian dilanjutkan dengan demontrasi praktik pemijatan bayi. Evaluasi kegiatan ini dilakukan pada masing-masing tahapan pemijatan.

Hasil dalam kegiatan training pijat bayi ini sesuai dengan kebutuhan ibu - ibu dalam membantu perkembangan bayi. Menfaat pijat bayi ini dapat membuat bayi merasa nyaman, dan relaks, pijat membuat otot - otot bayi menjadi renggang, pijat bayi dapat membantu konsentrasi, memicu perkembangan otak, meringankan pencernaan, dan membantu oksigen menuju ke otak. Adanya respon yang baik (80\%) ibu memahami pentingnya pijat bayi. Namun beberapa kekhawatiran yang dialami oleh peserta adalah mereka belum pernah melakukan pijatan pada bayinya, sehingga ibu merasa takut, namun tidak perlu dikhawatirkan dikarenakan kegiatan ini dapat dilakukan dengan santai di rumah dengan membaca Booklet dengan seksama. Hasil pengabdian masyarakat ini diharapkan mampu memotivasi dan menambah keterampilan ibu - ibu dalam pijat bayi.
\end{abstract}

Kata Kunci: Manfaat Pijat, pada Bayi, Perkembangan Bayi 
DINAMISIA - Jurnal Pengabdian Kepada Masyarakat $\quad$ Vol. 3, Special Issue Juni 2019, Hal. 49-52

\section{PENDAHULUAN}

Keputusan Menteri Kesehatan dengan nomor 900/MENKES/SK/VI/2002 tentang praktek dan registrasi bagi bidan ini menyebutkan bahwasannya Bidan berwenang dalam memantau tumbuh kembang bayi melalui stimulasi dan deteksi dini perkembangan. Salah satunya adalah pijat bayi. Sekelompok ilmuan di Venezuela melakuan penelitian tentang rancangan sentuhan kepada janin yang berada didalam kandungan, ketika menjelang persalinan sampai terjadinya kelahiran bayi, dalam pengamatan mereka tercatat adanya temuan tentang sentuhan yang berhubungan dengan pijat bayi. Mereka mengamati bahwa janin yang dari kandungan sering mendapat sentuhan maka ketika lahir bayi tersebut lebih lincah gerakkannya. Menurut dr. Utami Roesli dalam buku Yazid mengatakan bahwa terapi pijat bayi dapat menghasilkan perubahan fisiologi yang membantu kadar hormone dalam tubuh berperan aktif. Sehingga penemuan ini sangat dianjurkan untuk pekembangan selanjutnya. ${ }^{[4]}$

Pijat bayi ini telah dilakukan di Indonesia sejak dahulu kala, turun temurun tanpa diketahui bagaimana pijatan atau sentuhan berdampak positif bagi tubuh manusia. Bagian sentuhan adalah kulit, yaitu bagian yang teluas dari tubuh manusia, bayi dapat merasakan fungsi ini sejak dari kandungan. Ujung saraf pada permukaan kulit akan langsung bereaksi terhadap sentuhan yang diberikan. Beberapa kasus dengan bayi lahir prematur juga sangat efektif untuk dilakukan sentuhan lembut. ${ }^{[5]}$

Pijat bayi bisa dikatakan juga dengan terapi sentuh, dikarenakan adanya pijatan dan komunikasi yang baik dan nyaman antara ibu dan bayinya. Sentuhan ini memberikan pijatan yang ringan, sehingga bayi merasa aman dan nyaman. Banyak para ibu yang melakukan pijat bayi pada dukun bayi atau pijat tradisional. Beberapa dari mereka menganggap pijat ke dukun untuk menyembuhkan penyakit pada bayi mereka, pada kenyataannya pijat ini dapat dilakukan sendiri dengan ibu, ayah, atau sanak sodara lainnya yang merupakan pijatan terbaik karena adanya sentuhan kasih saying dari orang tua. ${ }^{[1,9]}$

Perkembangan dan pertumbuhan bayi akan optimal jika adanya interaksi antara genetik, tingkah laku, lingkungan dan rangsangan yang berguna. Pengaruh yang positif pada stimulus pijat ini telah lama dilakukan. Permasalahan pada gangguan pertumbuhan (Grow Faltering) pada anak di Indonesia sudah sejak usia 1 sampai 6 bulan, sehingga perlu adanya upaya dalam mengurangi gangguan perumbuhan yang dapat menghambat kenaikan berat badan bayi. ${ }^{[6]}$

Penelitian Lilik M, dkk 2014 mengatakan bahwa pijat bayi berpengaruh pada kuatitas tidur bayi, tidur bayi merupakan bagian penting untuk perkembangan bayi karena pada saat inilah terjadi repair neural-brain dan terjadi pertumbuhan hormon kurang lebih $75 \%$. Kebutuhan tidur bayi harus terpenuhi agar tidak berpengaruh terhadap perkembangannya, salah satu cara untuk membantu bayi tetap sehat adalah dengan melakukan pijat bayi. Terjadinya penigkatan tidur bayi karna pemijatan dipengaruhi karna hormon serotonim. Serotonim merupakan zat tansmittter utama yang serta merta ada ketika pembentukan tidur yang menekan otak. ${ }^{[7]}$

Hasil penelitian dari Pertiwi A, 2014, mengatakan bahwa dukungan keluarga sangat membantu dalam komunikasi verbal dan non verbal karena dampak emosional sang bayi yang sudah ia kenal. Hal ini tentu saja dapat membantuk bayi merasa lebih nyaman. Pada penelitian Devi, R. 2012, ibu yang melakukan pijat bayi secara mandiri dengan metode yang lengkap lebih signifikan dalam melakukan pijat bayi dibanding ibu yang hanya diberi leaflet saja, artinya pengetahuan ibu harus diasah dahulu untuk dapat menerima training dalam melakukan pijat bayi. Sehingga pijat bayi ini akan maksimal dilakukan dengan benar oleh peserta. Hasil survey yang ditemukan masih banyak ibu - ibu yang tidak pernah melakukan pijat bayi sendiri, mereka cenderung lebih percaya kepada dukun bayi atau pijat tradisional, sehingga pengabdi tertarik untuk memberikan training tentang pijat bayi. ${ }^{[8]}$

Tujuan dari kegiatan ini adalah untuk menambah pengetahuan tentang manfaat pijat bayi, dan dapat diaplikasikan dengan memijat langsung pada bayinya. Pada umumnya ibu - ibu masih merasa takut untuk melakuan pijat bayi sendiri dirumah. Sehingga kegiatan ini diharapkan mampu memberikan kepercayaan diri pada ibu - ibu untuk melakukan pijat bayi sendiri dirumah. 


\section{METODE}

Training yang diangkat dalam kegiatan pengabdian masyarakat ini bertujuan untuk meningkatkan motivasi dan keterampilan ibu dalam melakukan pijat bayi dirumah. Metode pembelajaran yang digunakan adalah Ceramah Tanya jawab dan Demonstrasi pijat bayi. Ceramah Tanya jawab ini dipilih pertama untuk memangun pengetahuan ibu tentang manfaat pijat bayi dan membangun motivasi ibu agar percaya diri untuk melakukan pijat bayi sendiri dirumah. Sasaran pada pengabdian masyarakat ini adalah ibu - ibu yang memiliki bayi 0-12 bulan di PMB Ernawati, Way Jepara. Sasaran ini ditujukan untuk 20 peserta.

Metode selanjutnya adalah Demonstrasi, metode ini dilakukan untuk memperjelas apa itu pijat bayi dan bagaimana cara melakukan pijat bayi dengan benar. Demonstrasi ini dilakuan denan Booklet pijat bayi, sehingga peserta akan lebih mudah mengingat gerakan - gerakan apa saja yang harus dilewati dalam pijat bayi. Setelah itu peserta dapat latihan melakukan pijat bayi secara langsung terhadap bayinya dengan benar.

Untuk mengetahui seberapa besar keberhasilan kegiatan pengabdian masyarakat ini dapat dilihat dari daftar hadir dan antusia peserta yang ikut selama kegiatan berlangsung. Para pesert antusias dalam mendengarkan dan melihat praktek melakukan pijat bayi. Training ini juga menggunakan angket untuk tingkat kepuasan peserta terhadap kegiatan pengabdian masyarakat.

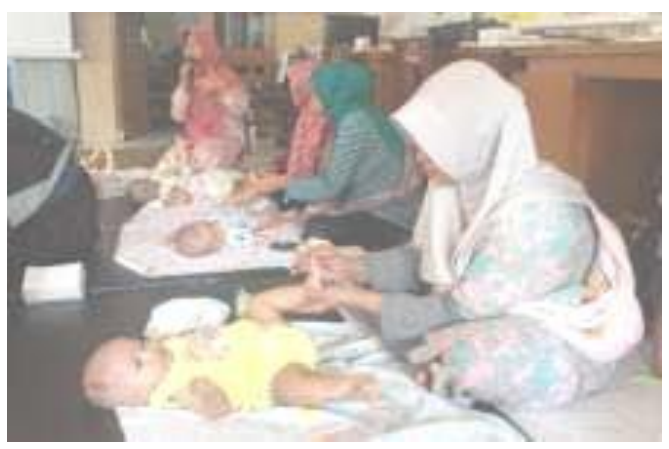

Gambar 1 Pengabdian

\section{HASIL DAN PEMBAHASAN}

Pelaksanaan kegiatan training pijat bayi ini membutuhkan bantuan tenaga dari para tenaga kesehatan untuk mendampingi para ibu dalam melakukan pijat bayi, training ini membutuhkan waktu 1 bulan untuk merancang, melaksanakan dan mengevaluasi kegiatan yang dilaksanakan pada bulan Februari 2019. Ada beberapa hal yang harus dibahas dalam hasil pengabdian ini, yaitu motivasi peserta yang semula kurang karna tidak percaya diri dalam melakukan pijat bayi ini. Selanjutnya adalah antusias para peserta setelah mendapatkan materi meningkat, dan mereka mau untuk melakukan pijat bayi, mereka menyimak materi dengan baik dengan terjadinya diskusi didalamnya.

Hal pertama yang harus diselesaikan adalah masalah motivasi. Hasil wawancara yang dilakukan dari beberapa peserta ini adalah $80 \%$ mengatakan tidak pernah melakukan pemijtan pada bayinya dikarenakan takut melakukan pijatan, dengan alasan anaknya masih terlalu kecil. Setelah diberikan gambaran tentang manfaat pijat bayi dan sangat mudah untuk dilakukan, para peserta menjadi tertarik untuk melakukan pijat bayi dirumah. Kesiapan diri perlu dilakukan untuk membuat peserta percaya diri dalam melakuan pemijatan.

Kedua adalah masalah antusias peserta dalam mengikuti training ini. Setelah diberikan motivasi terkait mudahnya pemijatan bayi, para peserta sangat berantusias dalam mengikuti training pijat bayi, beberapa alasan yang dilontarkan oleh para peserta adalah ingin meningkatkan keterampilan dalam melakukan pijat bayi dirumah. Agar anak mereka dapat tumbuh dengan optimal dan para peserta dapat memantau perembangan dengan mudah.

Saat training berlangsung, ada beberapa kendala seperti bayi rewel karna suhu ruangan yang meningkat, sehingga terasa lebih panas, beberapa peserta kesulitan dalam mengikuti training karena masih takut untuk memijat bayinya, dalam penelitian Nurwinda Saputri dkk tahun 2014 
DINAMISIA - Jurnal Pengabdian Kepada Masyarakat $\quad$ Vol. 3, Special Issue Juni 2019, Hal. 49-52

mengatakan bahwa tingkat pendidikan juga mempengaruhi prilaku ibu dalam melakukan pijat bayi. ${ }^{2}$ Namun masalah - masalah tersebut dapat diselesaikan dengan baik dan berjalan dengan lancar. Peserta juga merasa training ini masih belum maksimal jika dilakukan dalam waktu satu hari, namun pemijatan ini dapat dilakukan sedikit demi sedikit dengan membaca Booklet yang sudah disampaikan, sehingga peserta tidak perlu khawatir.

\section{KESIMPULAN}

Kegiatan training pijat bayi ini berbentuk laporan hasil berupa peningkatan pengetahuan ibu dan bertambahnya keterampilan ibu dalam melakukan pijat bayi. Keberhasilan ini dapat dilihat dari:

1. Terjadinya diskusi dari kegiatan pijat bayi.

2. Adanya respon yang positif terhadap kegiatan pijat bayi ini.

3. $80 \%$ peserta memahami pentingnya manfaat pijat bayi.

\section{SARAN}

Kegiatan pengabdian masyarakat ini tentunya banyak kekurangan yang dapat dibenahi dengan pengabdian lanjutan, sehingga adanya metode lain yang dapa membantu semakin maksimal untuk para peserta dalam melakukan pijat bayi.

\section{UCAPAN TERIMAKASIH}

Kegiatan pengabdian masyarakat ini berjalan dengan lancer karna beberapa pihak yang membantu dalam kegiatan ini. Penulis mengucapkan terimakasih kepada:

1. STIKes Muhammadiyah Pringewu Lampung

2. PMB Ernawati

3. Segenap Civitas Akademika

4. Dukungan keluarga.

\section{DAFTAR PUSTAKA}

[1] Sari, Nurul Indah., 2010, Efektifitas Pijat Bayi Terhadap Peningkatan Berat Badan Bayi Prematur DI Ruang Perinatologi RSU Dr. Pirngadi Medan. http://repository.usu.ac.id/handle/123456789/18796

[2] Saputri N, dan Sholeha, T., 2014, Tingkat Pedidikan Dengan Perilaku Ibu Dalam Melakukan Pijat Bayi. Jurnal Ilmiah Keperawatan IMELDA, Vol. 5, No. 1, Februari 2019. Hal 593

[3] Rismundari, Devi and Sri Sumaryani., 2012, Pengaruh Pendidikan Kesehatan Pijat Bayi terhadap Perilaku Ibu dalam Melakukan Pijat Bayi secara Mandiri di Posyandu Krikilan Ngaglik Sleman Yogyakarta.

[4] Subakti Y, Anggraeni DR., 2008, Keajaiban Pijat Bayi dan Balita. Jakarta: WahyuMedia. VIII+164 Hal.

[5] dr. Utami Roesli., 2012, Pedoman pijat bayi premature dan Bayi Usia 0-3 Bulan. Jakarta: Merantas Generasi Sehat.

[6] Dasuki, M. S., 2010, Pengaruh pijat bayi terhadap kenaikan berat badan bayi umur 4 bulan. http://etd.repository.ugm.ac.id/

[7] Mardiana L, Martini DE., 2014, Pengaruh Pijat Bayi Terhadap Kuantitas Tidur Bayi Usia 3-6 Bulan Di Desa Munungrejo Kecamatan Ngimbang Kabupaten Lamongan. Jurnal SURYA. Vol.02, No. XVIII, Juni

[8] PERTIWI A., 2016, Hubungan Tingkat Pengetahuan Ibu dengan Perilaku Pijat Balita di PUSKESMAS Kecamatan Marangkayu Kabupaten Kutai Kartanegara. https://dspace.umkt.ac.id//handle/463.2017/854 Riksani R. 2012. Cara mudah dan aman pijat bayi. Jakarta: Dunia Sehat 